\title{
ERCP practitioners in China: results from national surveys in 2007 and 2013
}

Authors

Institutions
Liang-Hao Hu H, * $^{1}$, Lei Xin ${ }^{1, *}$, Luo-Wei Wang ${ }^{1, *}$, Wei Qian ${ }^{1,2}$, Zhuan Liao ${ }^{1}$, Zhao-Shen Li ${ }^{1}$

${ }^{1}$ Digestive Endoscopy Center, Department of Gastroenterology, Changhai Hospital, Second Military Medical University, Shanghai, China

${ }^{2}$ Center for Clinical Epidemiology and Evidence-Based Medicine, Changhai Hospital, Second Military Medical University, Shanghai, China submitted: 13. June 2015 accepted after revision: 30. August 2015

\section{Bibliography}

Dol http://dx.doi.org/

10.1055/s-0035-1563805

Published online: 13.1.2016

Endoscopy 2016; 48: 358-363

(c) Georg Thieme Verlag KG

Stuttgart · New York

ISSN 0013-726X

Corresponding author

Zhao-Shen Li, MD, and Zhuan

Liao, MD

Digestive Endoscopy Center,

Department of

Gastroenterology

Changhai Hospital, Second

Military Medical University

168 Changhai Road, Shanghai, 200433

China

Fax: 86-21-55621735

zhaoshen-li@hotmail.com

zhuanliao@hotmail.com
Background and study aims: The endoscopist performing endoscopic retrograde cholangiopancreatography (ERCP) has an essential role in the development of that procedure. Given that the practice status and training background of Chinese ERCP practitioners (ERCPists) were largely unknown, two surveys were conducted to determine the status and development of this professional group.

Methods: National surveys were conducted by the Chinese Society of Digestive Endoscopy in 2007 and 2013. Information regarding numbers, demographic characteristics, practice status, and training background of ERCPists was collected.

Results: Total numbers of ERCPists in mainland China increased from 1155 to 3345 (0.88 to 2.47 per million inhabitants) between 2006 and 2012. Regional distribution of ERCPists showed significant imbalance, and the ERCPist - population ra-

\section{Introduction}

Endoscopic retrograde cholangiopancreatography (ERCP) was first introduced in 1968 and has been an effective tool in the diagnosis and treatment of biliary and pancreatic diseases $[1,2]$. The first ERCP in mainland China was performed in 1973 [3]. After four decades of development, ERCP services have been provided throughout China. However, a national survey showed that only 63787 ERCP procedures were performed in 2006 in 470 hospitals across mainland China, with an estimated annual ERCP rate of 4.87 per 100000 inhabitants, which was much lower than those of developed countries [4]. In that survey, shortage of ERCP endoscopists (ERCPists) was suggested to be a main factor restricting the development of the ERCP service. Moreover, in most developed countries, endoscopists intending to perform ERCP are required to undergo a tio correlated with gross domestic product per capita $(2006, r=0.871, P<0.001 ; 2012, r=0.452, P=$ $0.005)$. The mean (standard deviation) age of ERCPists decreased from 42.5 (6.1) years to 37.4 (5.4) years; the proportion of female ERCPists increased from $11.1 \%$ to $16.8 \%$. In 2006 and 2012 , annual ERCP volumes per endoscopist were 55.2 and 58.5, respectively, similar to that in most Western countries. The most common training pathway was participation in a training program in an ERCP center within China (2006, 51.1\%; 2012, 73.4\%); the proportion of ERCPists with no standard training decreased from $20.8 \%$ to $8.0 \%$. Conclusions: Between 2006 and 2012 in China there has been significant development in ERCP personnel and training. However, the shortage and regional imbalances are still obvious and a higher ERCP volume per endoscopist is needed.

standardized advanced endoscopic training program to obtain technical competence $[5,6]$, whereas China has no national standard for ERCPists or trainees, and the training pathway of ERCPists is unknown. Therefore, a survey to investigate the status of Chinese ERCPists would be beneficial for development of the ERCP service and the establishment of a standard training program. To address these issues, the Chinese Society of Digestive Endoscopy (CSDE) conducted a national survey of ERCPists in 2007 to determine the number, regional distribution, demographic characteristics, practice status, and training background of Chinese ERCPists. In 2013, the CSDE conducted another survey with a similar design to investigate the development of ERCPists in China. 


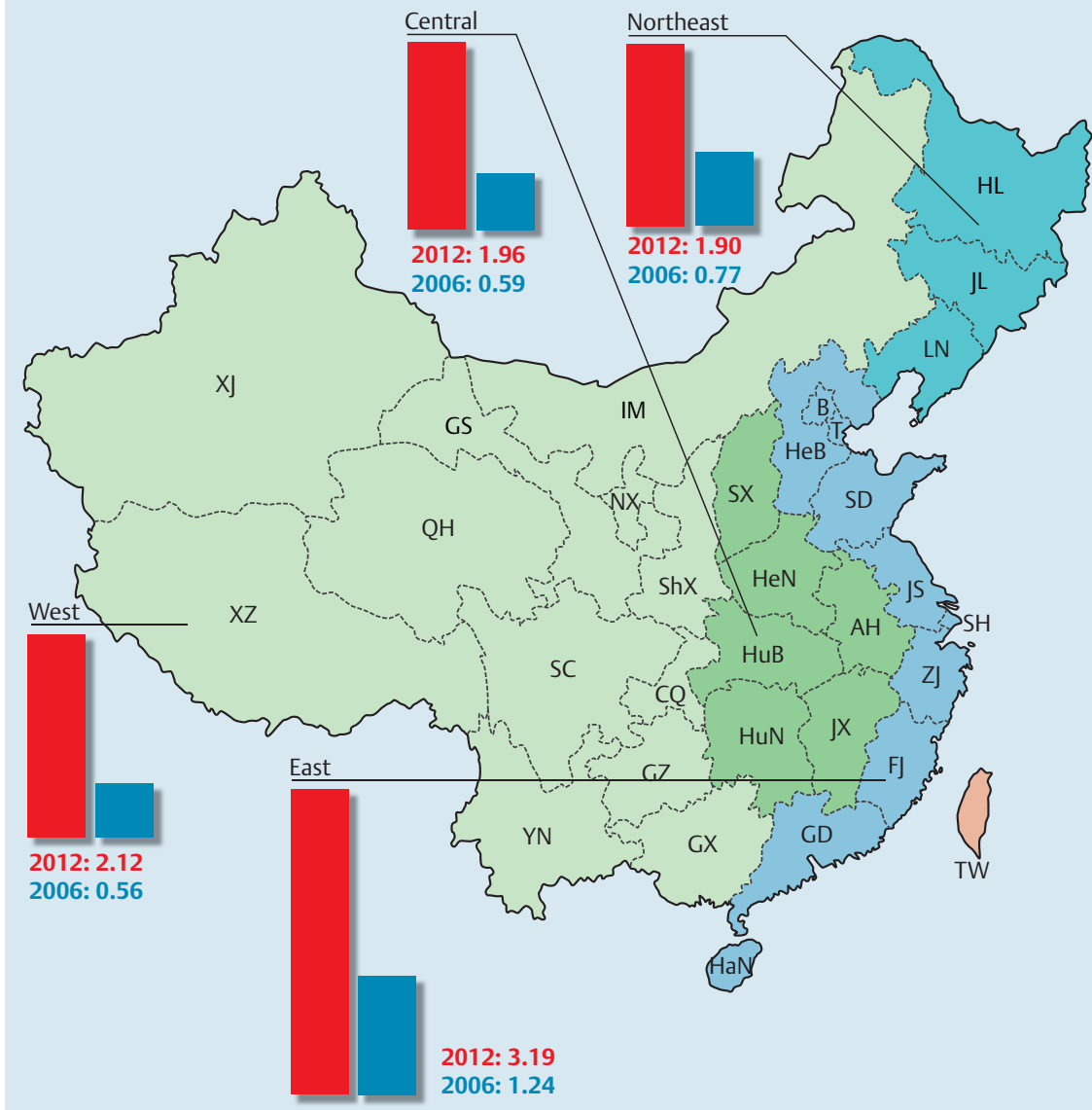

Fig. 1 Increase in the number of practitioners of endoscopic retrograde cholangiopancreatography (ERCP) per 1000000 inhabitants (ERCPist-to-population ratio) in mainland China between 2006 and 2012. (Northeast region: HL, Heilongjiang; JL, Jilin; LN, Liaoning. East region: BJ, Beijing; FJ, Fujian; GD, Guangdong; HaN, Hainan; HeB, Hebei; JS, Jiangsu; SD, Shandong; SH, Shanghai; TJ, Tianjin; ZJ, Zhejiang. Central region: AH, Anhui; HeN, Henan; HuB, Hubei; HuN, Hunan; JX, Jiangxi; SX, Shanxi. West region: GS, Gansu; GX, Guangxi; GZ, Guizhou; IM, Inner Mongolia; NX, Ningxia; QH, Qinghai; ShX, Shaanxi; SC, Sichuan; XZ, Tibet; XJ, Xinjiang; YN, Yunnan; CQ, Chongqing. HK, Hong Kong; MAC, Maocau; TW, Taiwan. This map does not show the complete territory of China.

\section{Methods}

\section{$\nabla$}

\section{The surveys}

The first and second surveys were conducted from October 2007 to March 2008 and from August 2013 to January 2014, respectively. The CSDE organized this study, and all of the 31 provincial branches in mainland China participated. Information on which hospitals could provide an ERCP service was retrieved by the CSDE branches through the local health authorities. The numbers and names of the ERCPists at the hospitals were retrieved from their designated senior endoscopists. In the first survey, predesigned structured questionnaires were sent to each senior endoscopist and were completed by each ERCPist. The senior ERCPist then collected and returned the questionnaires by mail to the CSDE headquarters in Shanghai for analysis. The second survey was conducted through online questionnaires.

After the questionnaires had been collected, approximately onefifth of the ERCPists involved were selected for data checking via simple random sampling. The involved CSDE branches collected the medical records or other official records from hospitals and carefully checked the data in the questionnaires. The results of the data check were then sent back to the organizer. When significant discrepancies were found between the checked data and the questionnaire, the questionnaire was considered invalid and was not included in the analysis. The data checks were finished in June 2008 and March 2014, respectively.

\section{Questionnaire items}

The items were completed according to the data in 2006 and 2012, respectively. Both questionnaires included information about: (i) demographic details and educational background of the ERCPist; (ii) duration of ERCP practice; and (iii) other endoscopic skills (e.g., colonoscopy, small-bowel endoscopy, endoscopic ultrasonography [EUS], and endoscopic submucosal dissection [ESD]). The first survey questionnaire included ERCP training background items, but the second survey questionnaire did not initially have this content. Therefore, to enable comparison, for the second survey this information was subsequently obtained from one-fifth of ERCPists nationwide who had been selected randomly.

In mainland China, three educational degrees are granted by medical schools. A bachelor's degree in medicine can be obtained after a 5-year full-time undergraduate course. A master's degree in medicine can be obtained after 3 or 4 years of postgraduate study, and another 3 or 4 years of study is required to obtain the doctorate degree in medicine. An individual with any of the three aforementioned degrees can apply for a license to practice medicine.

Fellowship positions are not available in China, and resident, attending, and chief physicians are the three titles (from the lowest to the highest rank) given to such medical practitioners. In high grade hospitals, a medical team consists of several physicians at the three levels. The chief physician is the leader of a medical team and the attending physician is the assistant, which is quite different from the role in Western countries.

The following pathways are available for Chinese endoscopists to learn ERCP: (i) participation in a standardized training program at an ERCP training center within China (always in a teaching hospital); (ii) learning from senior ERCPists in their own hospital (like the mentor - mentee relationship); (iii) participation in a standard training program at an overseas ERCP training center; and (iv) other nonstandard trainings. 


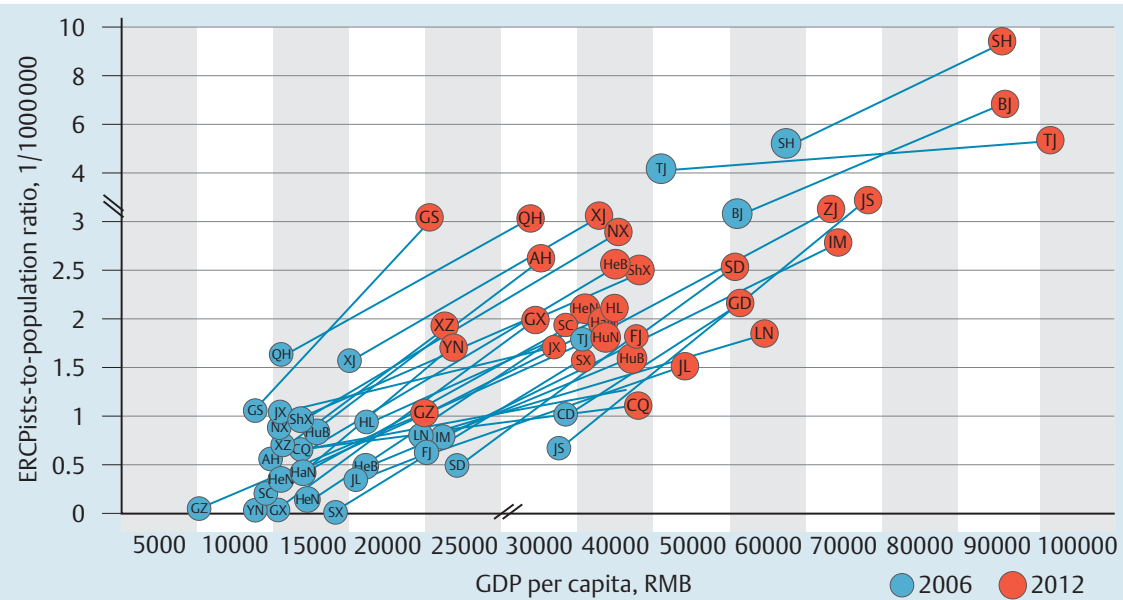

Fig. 2 Relationship between numbers of ERCP practitioners and gross domestic product (GDP) per capita (in renminbi $[R M B]$ ) in different regions in mainland China (2006, $r=0.871, P<0.001 ; 2012$, $r=0.452, P=0.005)$. The points represent the ERCPist-to-population ratios of various provinces in 2006 (blue points) and 2012 (red points). Both the $x$ - and $y$-axes of the graph have a different scale after the breaks (// and ||) in order to include the information more compactly. See Fig. 1 legend for the key to the abbreviations.

\section{Data collection and synthesis}

Data from the returned questionnaires were extracted and summarized in a database for further analysis. If a hospital provided an ERCP service but the senior endoscopist failed to return the relevant data then the number of ERCPists was retrieved from local health authorities by the corresponding CSDE branch.

The total number of ERCPists in mainland China was accumulated, and the ERCPist-to-population ratio (the number of ERCPists per 1 million inhabitants) was used as an index to reflect the adequacy of ERCPist numbers in a region (the population of a middle-sized town in China is approximately 1 million). In the analysis of ERCPist personnel development in various regions, we divided China into northeast, east, central, and western regions, reflecting the divisions used for socioeconomic analysis by the Chinese government.

The average ERCP procedure volume per endoscopist per annum was estimated and compared with data from the UK, Canada (using Alberta province as representative), Austria, Norway, the Netherlands, and Sweden, which were retrieved or calculated through published data resources [6-11].

To determine the correlation between the adequacy of numbers of ERCPists and the economic development in a provincial region, the ERCPist-to-population ratio and the gross domestic product (GDP) per capita were used as the main indexes. The GDP per capita of the 31 provincial regions of mainland China was retrieved from the China Statistical Yearbook $[12,13]$.

\section{Statistical analysis}

Categorical data are shown as percentages. A nonparametric correlation statistical test (one-sided Spearman's test) was used to analyze the correlations between the regional GDP per capita and the ERCPist-to-population ratio. Simple random sampling and statistical analyses were performed using SPSS version 13.0 for Windows (SPSS, Chicago, Illinois, USA). A two-sided $P$ value of $<0.05$ was considered to be statistically significant.

\section{Results \\ $\nabla$}

Total number and regional distribution of ERCPists

In mainland China, 1130 ERCPists practiced in 470 hospitals in 2006, and 3345 ERCPists practiced in 1156 hospitals in 2012. The ERCPist-to-population ratio increased from 0.88 to 2.47 per 1000000 inhabitants between 2006 and 2012.
- Fig. 1 shows the development of the ERCPist-to-population ratio in various regions between 2006 and 2012. 0 Fig. 2 shows the ERCPist-to-population ratio of each provincial region in 2012. An imbalanced regional distribution of ERCPists was found, and the ERCPist-to-population ratio correlated significantly with the GDP per capita (2006, $r=0.871, P<0.001 ; 2012, r=0.452, P=0.005)$.

\section{Response, demographic characteristics,} and educational background

In 2007, 584 (50.6\%) ERCPists returned the questionnaire and 577 ERCPists were qualified for further analysis after data checking, with an effective return rate of 50.0\%. In 2013, all of the 3345 ERCPists returned the questionnaire (this survey was supervised by the National Ministry of Health as part of the Chinese Digestive Endoscopy Census 2012), among whom 3328 were included for further analysis, with an effective return rate of $99.5 \%$.

In 2006, the proportion of female ERCPists was $11.1 \%(n=64)$, and this proportion increased to $16.8 \%(n=558)$ in 2012 . The mean (SD) ages of ERCPists were 42.5 (6.1) years and 37.4 (5.4) years in 2006 and 2012, respectively. The clinical titles and educational backgrounds of Chinese ERCPists are shown in $\bullet$ Table 1.

\section{ERCP case volume and length of experience}

The total ERCP volume per annum in mainland China increased from 63787 to 195643 between 2006 and 2012 (from a study published in Chinese), and the estimated annual mean ERCP volume of an endoscopist in mainland China increased from 55.2 (63 $787 / 1155)$ to 58.5 (195 643/3345). This result is similar to those in most Western countries ( $\bullet$ Fig. 3 ). The annual ERCP volume of male ERCPists was higher than that of female ERCPists (male/female: 2006, 58.0/33.0; 2012 63.4/35.7). In 2012, about twothirds of the endoscopists $(n=2213,66.5 \%)$ performed $<50$ ERCP procedures, 869 ERCPists (26.1\%) performed 50-200 ERCPs, and $246(7.4 \%)$ performed $>200$ ERCPs.

In 2006, $48.5 \%$ of Chinese ERCPists $(n=280)$ had practiced ERCP for $\leq 5$ years; $32.4 \%(n=187)$ for $6-10$ years; $16.7 \%(n=96)$ for $11-20$ years; and $2.4 \%(n=14)$ for $>20$ years. In 2012 , the corresponding proportions were: $\leq 5$ years, $60.1 \%(n=1999) ; 6-10$ years, $26.8 \%(n=891) ; 11-20$ years, $11.5 \%(n=383)$; and $>20$ years, $1.7 \%(n=55)$. 


\begin{tabular}{|c|c|c|}
\hline & $\begin{array}{l}\text { Proportion in 2006, \%* } \\
\text { (Responders, } \mathrm{n}=577 \text { ) }\end{array}$ & $\begin{array}{l}\text { Proportion in 2012, \%* } \\
\text { (Responders, } \mathrm{n}=3328 \text { ) }\end{array}$ \\
\hline Gender ratio, male:female & $8: 1$ & $5: 1$ \\
\hline \multicolumn{3}{|l|}{ Age, years } \\
\hline Mean (SD) & $42.5(6.1)$ & $37.4(5.4)$ \\
\hline \multicolumn{3}{|l|}{ By age range } \\
\hline$\leq 30$ & $1.7 \%$ & $1.8 \%$ \\
\hline 31 to 40 & $34.3 \%$ & $50.4 \%$ \\
\hline 41 to 50 & $54.9 \%$ & $34.6 \%$ \\
\hline 51 to 60 & $7.3 \%$ & $12.1 \%$ \\
\hline$>60$ & $1.7 \%$ & $1.1 \%$ \\
\hline \multicolumn{3}{|l|}{ Clinical level } \\
\hline Resident & $9.9 \%$ & $3.6 \%$ \\
\hline Attending physician & $26.9 \%$ & $55.2 \%$ \\
\hline Chief physician & $63.3 \%$ & $41.1 \%$ \\
\hline \multicolumn{3}{|l|}{ Degree } \\
\hline Bachelor of medicine & $48.9 \%$ & $47.3 \%$ \\
\hline Master of medicine & $29.3 \%$ & $30.4 \%$ \\
\hline Doctor of medicine & $21.8 \%$ & $22.3 \%$ \\
\hline
\end{tabular}

Table 1 Endoscopic retrograde cholangiopancreatography (ERCP) practitioners in mainland China: demographic characteristics, clinical title, and educational background.

SD, standard deviation

* Except where indicated

\begin{tabular}{r|cr}
\hline Canada (2001) & 111.0 \\
\cline { 2 - 3 } The Netherlands (2013) & \multicolumn{3}{|c}{70.0} \\
\hline United Kingdom (2004) & 41.0 \\
\hline Norway (2006) & 36.5 \\
\hline Sweden (2008) & 35.2 \\
\hline Austria (2006) & & 55.2 \\
\hline China (2006) & & \\
\hline China (2012) & & 58.2 \\
\hline Annual ERCP volume of an endoscopist in different countries
\end{tabular}

Fig. 3 Annual volume of endoscopic retrograde cholangiopancreatography (ERCP) procedures for an endoscopist in China and in Western countries.

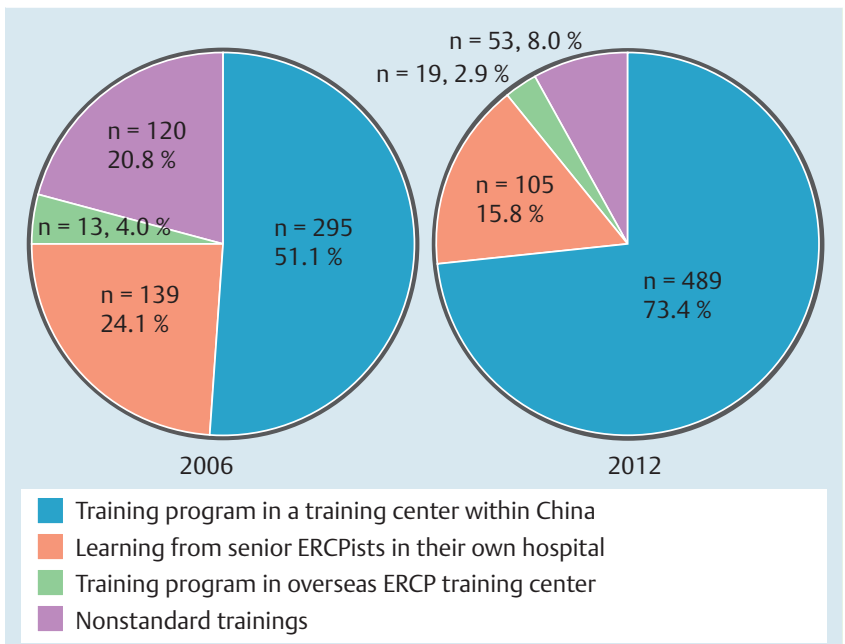

Fig.4 Training background of endoscopic retrograde cholangiopancreatography (ERCP) practitioners (ERCPists) in mainland China. The total numbers of ERCPists who participated in this part of the survey were 577 in 2007 and 666 in 2013.

\section{ERCP training background}

In 2006 and 2012, the most common training pathways were participation in a standardized training program in an ERCP training center within China (2006, 51.1\%; 2012, 73.4\%), and learning from senior ERCPists in the practitioner's own hospital (2006, 24.1\%; 2012, 15.8\%) (- Fig.4). From 2006 to 2012, the proportion of ERCPists with no standard training decreased from $20.8 \%$ to $8.0 \%$; this decrease was especially notable in the group of ERCPists who had been practicing ERCP for $\leq 5$ years ( $5 /$ $195,2.6 \%$.

\section{Other endoscopic skills}

In 2006, $75.2 \%$ of Chinese ERCPists could perform colonoscopy $(n=434) ; 8.3 \%(n=48)$ could perform small-bowel endoscopy; $18.4 \%(n=106)$ could perform EUS; and $1.6 \%(n=9)$ could carry out ESD. In 2012, these proportions increased to: colonoscopy, 86.3\% ( $n=2873)$; small-bowel endoscopy, $11.7 \%(n=388)$; EUS, $27.6 \%(n=918)$; and ESD, 32.6\% $(n=1086)$.

\section{Discussion}

$\nabla$

This report first showed the overall nationwide status of ERCPists in China. The findings suggest that the development and training of ERCPist personnel improved significantly in China between 2006 and 2012. In those 6 years, the ERCPist-to-population ratio almost tripled (from 0.88 to 2.47 per 1000000 inhabitants) and the proportion of ERCPists with a standard training background increased from $79.2 \%$ to $92.0 \%$. However, the shortage of ERCPists and the regional imbalances are still obvious and a higher ERCP volume per endoscopist is still needed.

ERCP has been developed for more than 40 years as an important technique for the diagnosis and treatment of cholangiopancreatic disease. In recent years, the role of ERCP has gradually changed from a diagnostic modality to a therapeutic one and the total volume has even decreased in some developed countries [14-16]. However, this is not the case in China. Despite a dramatic increase in its GDP, China is still a "developing country" rather than a developed one [17], and medical resources are relatively inadequate. In our previous study, the estimated annual ERCP 
rate in China was only 4.87 per 100000 inhabitants, which was much lower than that of developed countries (70-188 per 100 000 inhabitants) [4]; thus, the ERCP service needs substantial improvement in facilities and personnel. The situation regarding personnel has been considerably improved in recent years. The present study showed that the ERCPist-to-population ratio increased from 0.88 to 2.47 per 1000000 inhabitants between 2006 and 2012 (from 1130 in 2006 to 3345 in 2012). This finding suggests an average increment of 368 ERCPists per year. In particular, this advance is more obvious in the less developed central and western regions, where the increase has been approximately 3.5-fold ( $\bullet$ Fig. 2).

We consider the progress regarding ERCPists in China to be inspiring, but we also have to admit that the absolute numbers of ERCPists are far from adequate. The ERCPist-to-population ratio in 2012 was 2.47 per 1000000 inhabitants, suggesting that fewer than 3 ERCPists are available in a middle-sized town in China, whereas recent reports have shown that the ERCPist-to-population ratio in Sweden, the Netherlands, and Norway was around 20 per 100000 inhabitants [9-11]. Even if Cotton's estimation is adopted, in which $1 / 1000$ is used as the proportion of the average adult population undergoing ERCP and 150 ERCPs as the endoscopist's annual volume [18], approximately 6667 ERCPists are needed in mainland China (5.1 ERCPists per 1000000 inhabitants), which is almost double the current number. Moreover, the unbalanced regional distribution of ERCPists aggravates this shortage. In the two most developed regions (Shanghai and Beijing), the ERCPist proportion in 2012 was much higher than the national average (9.5 and 6.3 per 1000000 inhabitants), whereas in the two least developed regions (Chongqing and Guizhou), the ERCPist proportion in 2012 was less than 1.5 (1.3 and 1.1 per 1000000 inhabitants). In general, the more economically developed regions have higher ERCPist-to-population ratios ( $r=0.452, P=0.005$, for 2012$)$. Given this situation, provision of support to the central and western regions in terms of development of ERCPist personnel is still a priority.

The annual case volume of ERCPists has been a focus of study for a long time, and most studies have shown that ERCPists with a high volume of ERCPs tended to achieve greater technical success and fewer complications [19-21]. The present study showed that the estimated annual ERCP volumes of an endoscopist in China were 55.2 in 2006 and 58.5 in 2012, and nearly two-thirds (66.5\%) of the ERCPists performed fewer than 50 ERCP procedures annually, which would be categorized as "low volume" according to Coté et al. [22]. Although these figures are similar to those in most Western countries ( Fig.3) and seem acceptable for a developing country, further improvement is still necessary. As mentioned above, the number of ERCPists almost tripled from 2006 to 2012 and, in 2012, 60.1\% ERCPists had been practicing ERCP for $\leq 5$ years, which suggested that many Chinese ERCPists have only recently started their practice. As mentioned by Cotton [18], a very experienced ERCP practitioner could remain competent by performing approximately 50 ERCPs per year, but those who have only recently completed training are unlikely to perform adequately, let alone improve, without constant or increased ERCP practice. Therefore, we recommend that Chinese ERCPists should increase their annual volume to improve their performance and that those who intend to start ERCP practice should consider their potential annual volume.

Gender difference in practice has existed for a long time, but an increasing number of women are choosing gastroenterology as a profession in recent years [23-25]. In the analysis of demo- graphic details and practice of Chinese ERCPists, we found a significant increase in the proportion of female ERCPists (from $11.1 \%$ in 2006 to $16.8 \%$ in 2012 ). We recognize this as a positive trend. Although the annual ERCP case volume of female ERCPists was still less than that of male ERCPists (male/female case volume ratio was 58.0/33.0 in 2006 and 63.4/35.7 in 2012), this gap may be narrowed in the future as new technology and equipment would enable decreased radiation exposure and workload.

A training program is necessary for a physician to perform ERCP in the future. However, nationwide fellowship and standard endoscopic trainings are not yet available in mainland China. As a result, endoscopists who intend to learn ERCP would select various training pathways. As shown in these two surveys, participation in a standardized training program in an ERCP training center within China (2006, 51.1\%; 2012, 73.4\%) was the most common pathway. Most ERCP training centers in China are located in high grade teaching hospitals, which provide 4-month to 12month programs. The trainees usually learn ERCP through animal model/simulator practice, live demonstration, hands-on teaching, and performance of procedures under supervision, and they obtain certification through an examination. Moreover, a considerable number of ERCPists (2006, 24.1\%; 2012, 15.8\%) were trained by senior ERCPists at their own hospital (i.e., a mentor mentee relationship). The teaching method, duration, and qualification are partly standard and partly individualized according to the trainer and trainee. Notably, a fifth (20.8\%) of the ERCPists in 2006 claimed that they obtained ERCP skills through nonstandard training, which meant that nonstandard training practice, such as live demonstration and hands-on teaching, was the main pathway, and their qualifications were not certified by a training center or a senior trainer. We can speculate that nonstandard training would increase the risk associated with an ERCP procedure. Fortunately, amongst all ERCPists the proportion who followed this training pathway decreased to $8.0 \%$ in 2012, and the decrease was especially notable amongst those who had started their ERCP practice in the most recent 5 years (5/195, 2.6\%). Overall, ERCP training has improved significantly in China, but a national standard training for new ERCPists is still the main focus of the CSDE, considering the high demand for new ERCPists nationwide. The initial proposal for nationwide training networks included the Chinese College of Digestive Endoscopy and regional training centers. The Chinese College of Digestive Endoscopy aims to train the ERCP trainer and regional training centers are responsible for training the trainees in corresponding regions. All the endoscopists intending to start ERCP practice in the future should complete a standardized training program and their competency will be assessed.

This study has several limitations. First, adverse events were not included in both surveys. Given that both surveys were retrospective and self-reported by endoscopists, the true incidence of adverse events might have been inaccurate; thus, this content was abandoned. Adverse events are an important issue in ERCP quality control, and a national prospective survey or registry is necessary for future studies. Second, the difference in the method of data collection is a limitation. The first survey was conducted through paper questionnaire and mail, which restricted the return rate. After 2013, an electronic digestive endoscopy database was created in mainland China.

In conclusion, the practice and training of ERCPists have improved significantly in China between 2006 and 2012. However, the shortage and regional imbalances of ERCPists are still obvious and a higher ERCP volume per endoscopist is still needed. 


\section{Competing interests: None}

\section{References}

1 Adler DG, Baron TH, Davila RE et al. ASGE guideline: the role of ERCP in diseases of the biliary tract and the pancreas. Gastrointest Endosc 2005; 62: $1-8$

2 Williams EJ, Green J, Beckingham I et al. Guidelines on the management of common bile duct stones (CBDS). Gut 2008; 57: 1004-1021

3 Bai Y, Li ZS. Evolution of gastrointestinal endoscopy in the mainland of China. Chin Med J (Engl) 2009; 122: 2220-2223

4 Liao Z, Hu LH, Xin L et al. ERCP service in China: results from a national survey. Gastrointest Endosc 2013; 77: 39-46

5 Coyle WJ, Kedia PS, Kahaleh M. The advanced endoscopy fellowship match: an update and perspectives. Gastrointest Endosc 2012; 76: $1211-1213$

6 Williams EJ, Taylor S, Fairclough P et al. Are we meeting the standards set for endoscopy? Results of a large-scale prospective survey of endoscopic retrograde cholangio-pancreatograph practice Gut 2007; 56: $821-829$

7 Hilsden RJ, Romagnuolo J, May GR. Patterns of use of endoscopic retrograde cholangiopancreatography in a Canadian province. Can J Gastroenterol 2004; 18: 619-624

8 Kapral C, Duller C, Wewalka F et al. Case volume and outcome of endoscopic retrograde cholangiopancreatography: results of a nationwide Austrian benchmarking project. Endoscopy 2008; 40: 625-630

9 Glomsaker T, Søreide K, Aabakken L et al. A national audit of temporal trends in endoscopic retrograde cholangiopancreatography in Norway. Scand J Gastroenterol 2011; 46: 116-121

10 Enochsson L, Swahn F, Arnelo $U$ et al. Nationwide, population-based data from 11,074 ERCP procedures from the Swedish Registry for Gallstone Surgery and ERCP. Gastrointest Endosc 2010; 72: 1175-1184

11 Ekkelenkamp VE, de Man RA, Ter Borg F et al. Prospective evaluation of ERCP performance: results of a nationwide quality registry. Endoscopy 2015; 47: 503-507DOI 10.1055/s-0034-1391231 Epub 2015 Jan 15

12 China Statistical Yearbook 2013. Available from: http://www.stats.gov. cn/tjsj/ndsj/2013/indexeh.htm (Accessed: February 12 2015)

13 China Statistical Yearbook 2007. Available from: http://www.stats.gov. cn/tjsj/ndsj/2007/indexeh.htm (Accessed: February 12 2015)
14 Moffatt DC, Yu BN, Yie W et al. Trends in utilization of diagnostic and therapeutic ERCP and cholecystectomy over the past 25 years: a population-based study. Gastrointest Endosc 2014; 79: 615-622

15 Mazen Jamal M, Yoon EJ, Saadi A et al. Trends in the utilization of endoscopic retrograde cholangiopancreatography (ERCP) in the United States. Am J Gastroenterol 2007; 102: 966-975

16 Glomsaker T, Søreide $K$, Hoff $G$ et al. Contemporary use of endoscopic retrograde cholangiopancreatography (ERCP): a Norwegian prospective, multicenter study. Scand J Gastroenterol 2011; 46: 1144-1151

17 World Bank. China. Overview.http://www.worldbank.org/en/country/ china/overview (Accessed: March 12 2015)

18 Cotton PB. Are low-volume ERCPists a problem in the United States? A plea to examine and improve ERCP practice - NOW Gastrointest Endosc 2011; 74: 161 - 166

19 Kapral C, Duller C, Wewalka F et al. Case volume and outcome of endoscopic retrograde cholangiopancreatography: results of a nationwide Austrian benchmarking project. Endoscopy 2008; 40: 625-630

20 Peng C, Nietert PJ, Cotton PB et al. Predicting native papilla biliary cannulation success using a multinational Endoscopic Retrograde Cholangiopancreatography (ERCP) Quality Network. BMC Gastroenterol 2013; 13: 147

21 Coté GA, Imler TD, Xu H et al. Lower provider volume is associated with higher failure rates for endoscopic retrograde cholangiopancreatography. Med Care 2013; 51: 1040 - 1047

22 Coté GA, Keswani RN, Jackson T et al. Individual and practice differences among physicians who perform ERCP at varying frequency: a national survey. Gastrointest Endosc 2011; 74: 65-73

23 Long MT, Leszczynski A, Thompson KD et al. Female authorship in major academic gastroenterology journals: a look over 20 years. Gastrointest Endosc 2015; 81: 1440-1447.e3DOI 10.1016/j.gie.2015.01.032 Epub 2015 Apr 14

24 Singh A, Burke CA, Larive B et al. Do gender disparities persist in gastroenterology after 10 years of practice? Am J Gastroenterol 2008; 103: $1589-1595$

25 Hecht G. Women in gastroenterology: exciting times and trends. Gastroenterology 2008; 134: 913 -914 